\title{
ПОНЯТИЕ СЛУЖЕБНОГО ПОДЛОГА И ОТВЕТСТВЕННОСТЬ ЗА НЕГО В РОССИЙСКОМ ЗАКОНОДАТЕЛЬСТВЕ. РЕТРОСПЕКТИВНЫЙ АНАЛИЗ
}

\begin{abstract}
Аннотация: В статье рассматриваются основные подходы российских ученых дореволючионного периода в отношении юридического содержания служебного подлога, дается ретроспективный анализ формирования правило несении юридической ответственности за данное преступление.Автором была изучена дореволюционная практика рассмотрений уголовных дел о служебном подлоге российскими судами, что позволила выявить наиболее типичные случаи подлога в практике рассматриваемых уголовных дел. Кроме того, автором статьи проанализированы доктринальные источники, посвященные уголовно-правовому регулированию отношений возникаюших в связи со служебным подлогом - сочинения русских юристов дореволющионного периода Н.С.Таганцева и И.Я.Фойницкого, труды представителей советской науки уголовного права - А.Н.Трайнина, Т.Л. Сергеевой, В.М.Лебедева. При написании данной статьи использованы как общенаучные методы: метод формальной логики, историко-ретроспективного анализа, классификации, абстрагирования, индуктивный и дедуктивныйметоды и метод гипотезы, так и специиальные методы юридической науки: формально-юридический метод, метод исследования судебной практики метод правового моделирования, метод толкования правовых норм В статье отмечается, что российский законодатель всегда придерживается избирательного подхода при защите процедуры составления и оборота коммерческой документацииКроме того выделяются специифические особенности служебных подлогов характерных как для дореволюичонного российского законодательства, так и для современньх норм российского уголовного права о служебном подлоге. Таковыми выступают прежде всего направленность против установленного порядка документооборота в государственных (муниципальных) органах; налицо зависимость предмета от объекта преступного посягательства; наличие особого субъекта юридической ответственности за данное преступление - должностное лицьо, муниципальный (государственный) служашчии.Кроме того, таковым может выступать лицо, выполняющее управленческие функции. Автором сформулировано собственное юридическое определение служебного подлога.
\end{abstract}

Abstract: The article provides evaluation of the key approaches of the Russian pre-Revolution scholars regarding legal elements of the forgery by an official, the author provides a retrospective analysis of the formation of responsibility for this type of crime. The author has studied the pre-Revolution practice on criminal cases regarding forgery by an official in the Russian courts, allowing to single out the most typical forgery cases in the practice of criminal cases. In addition the author analyzes doctrinal sources, which are devoted to the criminal law regulation of the relations appearing due to the forgery by an official: works of the Russian lawyers of the pre-Revolution period, such as N.S. Tagantsev, I.Y. Foynitskiy, works of the representatives of the Soviet criminal law science, such as A.N. Traynin, T.L. Sergeeva, V.M. Lebedev. When writing this article the author involved general scientific methods, such as formal logical method, historical retrospective analysis, classification, abstraction, induction and deduction, hypothesis, as well as special legal methods: formal legal method, method of evaluation of the judicial practice, method of legal modeling, method of interpretation of legal norms. It is noted in the article that the Russian legislator always tends to be selective, when protecting the procedure of formation and turnover of commercial documents. In addition, the author singles out some specificities of forgery by an official, which are typical for the Russian criminal law on such forgery. These specificities include the purpose of an offence to act against the established order of document turnover in the official (municipal) bodies; presence of dependency of the immediate object from the object of criminal encroachment; presence of the special subject of criminal responsibility for such a crime: an official, a municipal (state) servant. In addition, it may also be a person implementing administrative functions. The author also provides her own definition of forgery by an official.

Ключевые слова: Служебный подлог, подлог, дореволюционное законодательство, документооборот, информация, дефиниция, исторический анализ, ложь, недостоверная информация, служебное преступление.

Keywords: Forgery by an official, forgery, pre-Revolution legislation, document turnover, information, definition, historical analysis, false, false information, crime by an official. 
DOI: $10.7256 / 1811-9018.2014 .10 .12891$

При цитировании этой статьи сноска на dоі обязательна

\section{Право и политика $10(178) \cdot 2014$}

П реступление, вне зависимости от того, совершенно оно посредством действия или же бездействия, заключается в едином смысле - в посягательстве на конкретный объект ${ }^{1}$. Объект преступления характеризуется как базовое определение в отечественной уголовной науке. То, как совершалось преступление, какую опасность оно в себе содержит, определяется в основном ключе объектом, на которое было обращено посягательство ${ }^{2}$.

Преступление, предусмотренное статьей 292 УК РФ, совершается путем предметной лжи как специфического действия. При служебном подлоге осуществляется искажение официального документа, придание ему ненадлежащего вида путем составления подложного документа (то есть подделки подлинного) либо изменения подлинного (то есть переделки). Это так называемый материальный подлог. Ложь может заключаться не только в словесном, но и в предметном искажении истины, когда путем определенных действий тому или иному предмету придается вид, не соответствующий надлежащему, то есть тому, который должен быть на самом деле.

Предметная ложь как специфическое действие возможна в двух разновидностях: во-первых, это переделка, заключающаяся в изменении настоящего вида определенного предмета; во-вторых, это подделка, заключающаяся в создании нового предмета, имеющего вид подлинного.

Обращаясь к истории вопроса, следует отметить мнение русского криминалиста Н.С. Таганцева, объясняющего суть ценности обращения к прошлому опыту законодательного творчества, которое заключается в том, что изучение исторического периода выступает основным способом понимания современного законодательства и права ${ }^{3}$.

Для всех служебных преступлений Уложения в качестве субъекта выступает должностное или находящееся на службе лицо. Таковым признается любой субъект, который занимает исполняющие обязанности, заключающиеся в несении государственной или коллективной службы с выполнением определенных поручений, возложенных на него, вне зависимости от того, имеет ли данное лицо конкретные полномочия или же он занимает договорную должность.

${ }^{1}$ Трайнин А.Н. Избранные труды. - СПб.: Изд-во «Юридический центр Пресс», 2004. - С. 71.

2 Расторопов С.В. Понятие объекта преступления: история, состояние, перспектива // Уголовное право. - 2002. - № 1. - С. 37.

${ }^{3}$ Таганцев Н.С. Русское уголовное право. Лекции: Часть общая: В 2-х т. Т. 1 / Таганцев Н.С.; Сост. и отв. ред.: Загородников Н.И. - М.: Наука, 1994. - С. 25-26.
Под характеристикой коллективно-общественной службы в законодательстве имелось в виду не определенное занятие в коммерческих учреждениях, а службу в организациях, для которых, в силу правовой регламентации, отдается власть по ведению задач местного самоуправления, а для управленцев и служащих таких организаций предусмотрены надлежащие обязанности по исполнению власти ${ }^{4}$.

Подлог, совершенный на службе, традиционно рассматривался в российском уголовном праве как преступление ${ }^{5}$. В главе четвертой «О подлогах по службе» различные виды подлога определялись в ст. 361-365 Уложения.

Подлог означал не всякий лживый поступок, а лишь «подделку документальную» ${ }^{6}$. Подлог в документах охватывал собой изготовление фальшивой подписи на документе, создания документа от имени лица, которое не имеет к данным бумагам никакого отношения, совершение незаконных сделок, внесение в документы недостоверной информации, изготовление мнимой копии с документа, которого не существует, а также подделки, документы с искаженными данными и др.

В то же время изготовление фальшивых документов не рассматривалось как служебный подлог, поскольку новый документ утрачивал признаки документа официального. Такие действия квалифицировались по ст.294 вне зависимости от субъекта, данные действия совершившего.

Служебный подлог считался произведенным, как только были внесены ложные сведения в документ, вне зависимости от последующих действий с данным документом с недостоверной информацией.

Для рассматриваемого вида служебного подлога было не обязательно, чтобы лицо осуществило действия, которые входили в его компетенцию. Поступки виновного квалифицировались по ст. 362 Уложения и в том случае, когда было совершено служебное преступление.

Лица, не относящиеся к числу служащих, участвовавшие в должностном подлоге, несли ответственность не по ст. 362, а по ст. 294 Уложения, если преступление охватывалось диспозицией указанной нормы. В то же время частное лицо, работающее по договору, за содеянное преступление о служебном подлоге несло ответственность по ст. 362 Уложения.

\footnotetext{
4 Уложение о наказаниях уголовных и исправительных 1885 года. Издание семнадцатое, пересмотренное и дополненное. - Петроград: Гос. типография. Издано Н.С. Таганцевым. 1913. - С. 389.

5 Там же. С. 390.

${ }^{6}$ Фойницкий И.Я. Курс уголовного права. - С. - Пб.: Тип. М.М. Стасюлевича, 1907. - C. $261,262$.
} 
DOI: $10.7256 / 1811-9018.2014 .10 .12891$

При цитировании этой статьи сноска на dоі обязательна

История государства и права

Согласно ч. 1 ст. 294 Уложения, противоправными документами, свидетельствующими о совершении служебного подлога, незаконных сделок, составления актов, предписаний и еще каких-либо официальных бумаг от имени Губернских Правлений и других судебных и правительственных мест или руководства, или закрепленных законодательством общественных организаций, а в равной мере злостных подчистках, поправках или иных изменениях и в использовании незаконно составленных или модифицированных документах, признавались бумаги, носящие официальный характер, распространяющиеся от имени власти в лице указанных органов и лиц, которые занимают ответственный пост в конкретной организации, где было совершено противоправное действие.

Данное преступное деяние, как отмечается в судебных документах, проявлялось в:

1) своевольном присвоении служебным лицом полномочий вне своей компетенции, одного или более прав ответственных лиц, приведенных в расположении, через составление официального подложного документа;

2) в намеренной модификации документа, содержание которого носит официальный характер и нарушает права учреждения либо лица, служащего в нем.

Преступление носило «универсальный» характер и применялось исключительно в отношении частных лиц, в том числе и в случаях, когда такое лицо участвовало в подлогах, совершаемых должностными лицами. Как указывает Н.С. Таганцев, в подлоге, совершенном несколькими лицами, необходимо подразумевать по самой сути данного преступления предварительное соглашение этих лиц 7 . Исходя из этого, частное лицо за использование или приобретение подложных документов ответственности не несло.

В марте 1903 года императором было утверждено Уголовное уложение, в соответствии со ст. 667 которого уголовной ответственности подлежал служащий, вина которого заключалась в:

1) в обращении с документом об отчетности при внесении в него заведомо недостоверных данных и обстоятельств;

2) во внесении в расчетные книги записей, содержащих в себе неверные данные о денежных операциях или каких-либо других записей, содержащих в себе важную информацию для управления средствами организации.

Данная норма имела существенные отличия от содержащейся в Уложении 1885 года ст. 362. Статья 362

\footnotetext{
7 Уложение о наказаниях уголовных и исправительных 1885 года. Издание семнадцатое, пересмотренное и дополненное. - Петроград: Гос. типография. Издано Н.С. Таганцевым. 1913. - С. 1115.
}

предусматривала уголовную ответственность за служебный подлог официальных документов.

Напротив, в п. 1 ст. 667 Уложения 1903 г. отсутствовало прямое указание закона на то, что предметом преступления мог быть только официальный документ, из чего можно сделать вывод, что предметом преступления, предусмотренного п. 1 ст. 667 Уложения 1903 г., выступал любой документ. Поэтому наказуемым деянием являлся подлог любого документа, составляемого в связи с занимаемым лицом служебным положением, в котором заведомо неверно излагались обстоятельства, которые таким документом удостоверяются.

В ч. 2 ст. 667 Уложения 1903 г. фактически воспроизводились положения ст. 358 Уложения 1885 г., в соответствии с которой уголовной ответственности подвергались служащие, которые заносили в отчетность недостоверные данные о приходе средств либо вовсе их не фиксировали. Однако в связи с указанием законодателя на такой предмет подлога как «иные записи, имеющие существенное значение для порядка управления», можно сделать вывод, что ч. 2 ст. 667 Уложения 1903 г. имела более широкое применение по сравнению со ст. 358 Уложения 1885 г $^{8}$.

Уложение 1903 г. в уголовной науке воспринимается как законодательная регламентация уголовной ответственности, имеющая весьма противоречивый характер. Это объясняется тем, что в отдельных нормах уголовной ответственности закреплено наказание за индивидуально-определенные виды преступлений.

Помимо ст. 667 в Уложении 1903 г. в главе 21 «О подлоге» (ст.ст.337-352) содержался подробный перечень подделок, ответственность за которые при определенных условиях могли нести и должностные лица.

Следует отметить, что отечественный законодатель выборочно защищает порядок составления и оборота коммерческой документации, поэтому в УК РФ не содержится статьи, аналогичной норме, предусматривающей ответственность за служебный подлог, которой охранялся бы порядок оборота любого коммерческого документа, предоставляющего определенные права или освобождающего от обязанностей, либо удостоверяющего юридически значимые факты и обстоятельства9.

Подлежащие охране коммерческие документы прямо называются законодателем:

\footnotetext{
${ }^{8}$ Таганцев Н.С. Русское уголовное право. Лекции: Часть общая: В 2-х т.. Т. 1 / Таганцев Н.С.; Сост. и отв. ред.: Загородников Н.И. - М.: Наука, 1994. - С. 25-26.

9 Питикин Р.А. Понятие подлога: законодательный и доктринальный подходы // Мониторинг правоприменения. - 2013. №4. - C. 68-72
} 
DOI: $10.7256 / 1811-9018.2014 .10 .12891$

При цитировании этой статьи сноска на dоі обязательна

\section{Право и политика $10(178) \cdot 2014$}

- реестр владельцев ценных бумаг или системы депозитарного учета;

- документы, необходимые для создания организации;

- проспект ценных бумаг; отчет (уведомление) об итогах выпуска ценных бумаг;

- протокол общего собрания; протокол заседания совета директоров (наблюдательного совета);

- документы, отражающие ход и результаты голосования; кредитные или дебетовые карты, другие документы систем оплаты;

- бухгалтерские и иные учетные бумаги, характеризующие материально-ответственную деятельность юридического лица;

- налоговая декларация, иные налоговые документы.

Перечень таких документов является исчерпывающим и определяется гражданским, налоговым законодательством, а также законодательством о рынке ценных бумаг ${ }^{10}$.

В тех случаях, когда предметом подлога выступают официальные документы, представляется целесообразным систематизировать рассматриваемые деяния в зависимости от того, в качестве основного, дополнительного или факультативного непосредственного объекта уголовного посягательства выступает определенный порядок оборота официальных документов, закрепленный законодательством ${ }^{11}$.

По мнению Т.Л. Сергеевой, нарушая подлинность и истинность документов, преступник тем самым посягает на определенный механизм взаимоотношений, который был закреплен в отечественном социалистическом обществе для достоверности тех актов, событий и фактов, которые имеют юридическое значение. Такого рода система общественных отношений и является непосредственным объектом посягательства при всякого рода подлогах документов ${ }^{12}$.

Н.А. Лопашенко справедливо отметила, что нематериальные блага также иногда могут быть предметом преступных посягательств, например составов служебного подлога (ст. 292 УК РФ) $)^{13}$. Действительно, офи-

\footnotetext{
${ }^{10}$ Питикин Р.А. Вопросы повышения качества применения норм, предусматривающих ответственность за служебный подлог // Юридическая наука и практика. - 2013. - № 22. - С. 261-264.

${ }^{11}$ Питикин Р.А. К вопросу о классификации служебных подлогов // Юридическая наука и практика : Вестник Нижегородской академии МВД России. - 2013. - № 21. - С. 233-235.

12 Сергеева T.Л. Борьба с подлогами документов по советскому уголовному праву. - М.- Л., Изд-во АН СССР, 1949. - С. 33.

13 Лопашенко Н.А. Преступления в сфере экономики: Авторский комментарий к уголовному закону (раздел VIII УК РФ). - М.: Волтерс Клувер, 2006. - С. 45-46.
}

циальные документы не имеют стоимости и не могут быть предметом сделок.

По мнению В.М. Лебедева, о юридически значимых фактах может свидетельствовать информация, запечатленная на различных материальных носителях. Однако такие носители и запечатленная на них информация, даже отвечающая перечисленным требованиям, могут быть предметом подлога как оконченного преступления лишь в том случае, когда они имеют непосредственное удостоверительное значение ${ }^{14}$.

Если же информация должна быть перенесена на другой носитель или не имеет юридического значения без соответствующего письменного акта, то искажение такого «документа» может рассматриваться только как предварительная преступная деятельность либо содержащая иной состав преступления (например, предусмотренный ст. 272 УК) ${ }^{15}$.

Т.Л. Сергеева писала, что в общем виде документ, являющийся предметом подлога, может быть определен как письменный акт, предназначенный при его создании или при подлоге служить удостоверением действительных или ложных событий или фактов, имеющих юридическое значение ${ }^{16}$.

Рассматривая данное Т.Л. Сергеевой определение документа, следует прийти к выводу, что в нем объединены два вопроса:

1) что такое документ;

2) подлинный ли он.

Представляется, что два эти вопроса должны быть логически разделены. Совершенно очевидно, что определение документа не может включать указание на то, удовлетворяет ли соответствующий документ своему назначению, ибо это уже вполне самостоятельный вопрос. Документ, который вследствие подделки не удовлетворяет своему назначению подлинного документа, не может быть предметом подлога.

Поэтому один из признаков официальности означает, что документ как носитель информации, имеющей юридическое значение, исходит от государственной или муниципальной организации либо от частных лиц или негосударственных организаций, но находится в

\footnotetext{
${ }^{14}$ Комментарий к Уголовному кодексу Российской Федерации (постатейный) (13-е издание, переработанное и дополненное) // отв. ред. В.М. Лебедев. - М.: «Юрайт», 2013.

${ }^{15}$ Питикин Р.А. Понятие подлога: законодательный и доктринальный подходы // Мониторинг правоприменения. - 2013. №4. - С. 68-72.

${ }^{16}$ Сергеева Т.Л. Борьба с подлогами документов по советскому уголовному праву. - М.- Л., Изд-во АН СССР, 1949. - С. 33.
} 
DOI: $10.7256 / 1811-9018.2014 .10 .12891$

При цитировании этой статьи сноска на dоі обязательна

История государства и права

ведении (делопроизводстве) государственной (муниципальной) организации ${ }^{17}$.

Обобщая высказанные учеными мнения, сформулируем свое определение понятия служебного подлога - это умышленное искажение должностным лицом, а также государственным служащим или служащим органа местного самоуправления, не являющегося должностным лицом, подлинности официального документа с целью употребления его под видом настоящего.

Таким образом, принимая во внимание ретроспективный аспект исследуемого вопроса, представляется целесоо- бразным выделить основные черты служебных подлогов как на этапе становления, так и на современном этапе развития:

а) все они посягают на установленный порядок документооборота в государственной и муниципальной либо в экономической сфере;

б) объект служебных подлогов напрямую зависит от предмета преступления;

в) за данные преступления может нести ответственность только специальный субъект - должностное лицо, муниципальный или государственный служащий, либо лицо, выполняющее управленческие функции.

\section{Библиография:}

1. Комментарий к Уголовному кодексу Российской Федерации (постатейный) (13-е издание, переработанное и дополненное) // отв. ред. В.М. Лебедев. - М.: «Юрайт», 2013.

2. Коробеев А.И. Полный курс уголовного права. - С. - Пб.: Юрид. центр Пресс, 2008. - 682 с.

3. Лопашенко Н.А. Преступления в сфере экономики: Авторский комментарий к уголовному закону (раздел VIII УК РФ). Волтерс Клувер, 2006.

4. Питикин Р.А. Вопросы повышения качества применения норм, предусматривающих ответственность за служебный подлог // Юридическая наука и практика. - 2013. - № 22. - С. 261-264.

5. Питикин Р.А. К вопросу о классификации служебных подлогов // Юридическая наука и практика: Вестник Нижегородской академии МВД России. - 2013. - № 21. - С. 233-235.

6. Питикин Р.А. Понятие подлога: законодательный и доктринальный подходы // Мониторинг правоприменения. - 2013. №4. - С. 68-72.

7. Расторопов С.В. Понятие объекта преступления: история, состояние, перспектива // Уголовное право. - 2002. - № 1. - С. 37.

8. Сахибуллин Р.Н. Объективная сторона и ее содержание в составе слу-жебного подлога // Вестник экономики, права и социологии. - 2014. - № 1. - С. 96-100.

9. Сергеева Т.Л. Борьба с подлогами документов по советскому уголовному праву. - М. - Л., Изд-во АН СССР, 1949. - С. 33.

10. Таганцев Н.С. Русское уголовное право. Лекции: Часть общая: В 2-х т.. Т. 1 / Таганцев Н.С.; Сост. и отв. ред.: Загородников Н.И. - М.: Наука, 1994. - 380 с.

11. Трайнин А.Н. Избранные труды. - СПб.: Изд-во «Юридический центр Пресс», 2004. - С. 71.

12. Уложение о наказаниях уголовных и исправительных 1885 года. Издание семнадцатое, пересмотренное и дополненное. Петроград: Гос. типография. Издано Н.С. Таганцевым. 1913. - С. 389.

13. Фойницкий И.Я. Курс уголовного права. - С. - Пб.: Тип. М.М. Стасюлевича, 1907. - 442 с.

14. Долгих И.П., Шебанов Д.В. Об оптимизации понятия «хищение» в российском законодательстве // NB: Вопросы права и политики. - 2014. - 5. - C. 23-37. DOI: 10.7256/2305-9699.2014.5.11933. URL: http://www.e-notabene.ru/lr/ article_11933.html

15. Никулин В.В. Партийно-государственная номенклатура и закон в советской России: двойная ответственность или особые правовые условия(1920-е годы) // NB: Исторические исследования. - 2013. - № 3. - C.1-43. DOI: 10.7256/2306420X.2013.3.750. URL: http://e-notabene.ru/hr/article_750.html

16. Бакрадзе А.А. Уголовно-правовой анализ проекта постановления Пленума Верховного Суда РФ «О судебной практике по делам о взяточничестве, коммерческом подкупе и иных коррупционных преступлениях» // NB: Boпросы права и политики. - 2013. - № 5. - C.165-180. DOI: 10.7256/2305-9699.2013.5.793. URL: http://e-notabene. $\mathrm{ru} / \mathrm{lr} /$ article $793 . \mathrm{html}$

17. Яровенко В.В., Атанова К.А. Криминалистическая экспертиза подделки // NB: Вопросы права и политики. - $2013 .-$ № 3. - C.318-329. DOI: 10.7256/2305-9699.2013.3.612. URL: http://e-notabene.ru/lr/article_612.html

18. Букалерова Л.А., Фортуна К.А.. К вопросу о наказаниях за коррупционные служебные подлоги // Административное и муниципальное право. - 2012. - № 6. - С. 104-107

19. Долгих И.П., Шебанов Д.В. Об оптимизации понятия «хищение» в российском законодательстве // NB: Вопросы права и политики. - 2014. - 5. - C. 23 - 37. DOI: 10.7256/2305-9699.2014.5.11933. URL: http://www.e-notabene.ru/lr/ article_11933.html

${ }^{17}$ Питикин Р.A. Понятие подлога: законодательный и доктринальный подходы // Мониторинг правоприменения. - 2013. №4. - С. 68-72. 
DOI: $10.7256 / 1811-9018.2014 .10 .12891$

При цитировании этой статьи сноска на доі обязательна

\section{Право и политика $10(178) \cdot 2014$}

\section{References (transliterated):}

1. Kommentarii k Ugolovnomu kodeksu Rossiiskoi Federatsii (postateinyi) (13-e izdanie, pererabotannoe i dopolnennoe) // otv. red. V.M. Lebedev. - M.: "Yurait", 2013.

2. Korobeev A.I. Polnyi kurs ugolovnogo prava. - S. - Pb.: Yurid. tsentr Press, 2008. - 682 c.

3. Lopashenko N.A. Prestupleniya v sfere ekonomiki: Avtorskii kommentarii k ugolovnomu zakonu (razdel VIII UK RF). - Volters Kluver, 2006.

4. Pitikin R.A. Voprosy povysheniya kachestva primeneniya norm, predusmatrivayushchikh otvetstvennost' za sluzhebnyi podlog // Yuridicheskaya nauka i praktika. - 2013. - № 22. - S. 261-264.

5. Pitikin R.A. K voprosu o klassifikatsii sluzhebnykh podlogov // Yuridicheskaya nauka i praktika: Vestnik Nizhegorodskoi akademii MVD Rossii. - 2013. - № 21. - S. 233-235.

6. Pitikin R.A. Ponyatie podloga: zakonodatel’nyi i doktrinal’nyi podkhody // Monitoring pravoprimeneniya. - 2013 . - №4. - S. 68-72.

7. Rastoropov S.V. Ponyatie ob”ekta prestupleniya: istoriya, sostoyanie, perspektiva // Ugolovnoe pravo. - 2002. - № 1. - S. 37.

8. Sakhibullin R.N. Ob"ektivnaya storona i ee soderzhanie v sostave slu-zhebnogo podloga // Vestnik ekonomiki, prava i sotsiologii. - 2014. - № 1. - S. 96-100.

9. Sergeeva T.L. Bor'ba s podlogami dokumentov po sovetskomu ugolovnomu pravu. - M. - L., Izd-vo AN SSSR, 1949. - S. 33.

10. Tagantsev N.S. Russkoe ugolovnoe pravo. Lektsii: Chast' obshchaya: V 2-kh t.. T. 1 / Tagantsev N.S.; Sost. i otv. red.: Zagorodnikov N.I. - M.: Nauka, 1994. - 380 c.

11. Trainin A.N. Izbrannye trudy. - SPb.: Izd-vo «Yuridicheskii tsentr Press», 2004. - S. 71.

12. Foinitskii I.Ya. Kurs ugolovnogo prava. - S. - Pb.: Tip. M.M. Stasyulevicha, 1907. - 442 c.

13. Dolgikh I.P., Shebanov D.V. Ob optimizatsii ponyatiya "khishchenie" v rossiiskom zakonodatel'stve // NB: Voprosy prava i politiki. - 2014. - 5. - C. 23-37. DOI: 10.7256/2305-9699.2014.5.11933. URL: http://www.e-notabene.ru/lr/article 11933.html

14. Nikulin V.V. Partiino-gosudarstvennaya nomenklatura i zakon v sovetskoi Rossii: dvoinaya otvetstvennost' ili osobye pravovye usloviya(1920-e gody) // NB: Istoricheskie issledovaniya. - 2013. - № 3. - S.1-43. DOI: 10.7256/2306-420X.2013.3.750. URL: http://e-notabene.ru/hr/article_750.html

15. Bakradze A.A. Ugolovno-pravovoi analiz proekta postanovleniya Plenuma Verkhovnogo Suda RF «O sudebnoi praktike po delam o vzyatochnichestve, kommercheskom podkupe i inykh korruptsionnykh prestupleniyakh» // NB: Voprosy prava i politiki. - 2013. - № 5. - S.165-180. DOI: 10.7256/2305-9699.2013.5.793. URL: http://e-notabene.ru/lr/article_793.html

16. Yarovenko V.V., Atanova K.A. Kriminalisticheskaya ekspertiza poddelki // NB: Voprosy prava i politiki. - 2013. - № 3. - S.318329. DOI: 10.7256/2305-9699.2013.3.612. URL: http://e-notabene.ru/lr/article_612.html

17. Bukalerova L.A., Fortuna K.A.. K voprosu o nakazaniyakh za korruptsionnye sluzhebnye podlogi // Administrativnoe i munitsipal'noe pravo. - 2012. - № 6. - S. 104-107

18. Dolgikh I.P., Shebanov D.V. Ob optimizatsii ponyatiya "khishchenie" v rossiiskom zakonodatel'stve // NB: Voprosy prava i politiki. - 2014. - 5. - C. 23 - 37. DOI: 10.7256/2305-9699.2014.5.11933. URL: http://www.e-notabene.ru/lr/article_11933.html 